\title{
Erratum to: Comprehensive evaluation of CT pulmonary angiography for patients suspected of having pulmonary embolism
}

\author{
Yen-Ting Lin • I-Chen Tsai • Wei-Lin Tsai • \\ Tain Lee $\cdot$ Min-Chi Chen $\cdot$ Pao-Chun Lin • \\ Si-Wa Chan
}

Published online: 22 January 2010

(C) Springer Science+Business Media, B.V. 2010

\section{Erratum to: Int J Cardiovasc Imaging DOI 10.1007/s10554-009-9573-8}

Due to an unfortunate misunderstanding, errors were introduced in the above mentioned article.

The first two authors contributed equally to this article.

This research was supported in part by Taichung Veterans General Hospital under grant number TCVGH-985506C.

The online version of the original article can be found under doi:10.1007/s10554-009-9573-8.

Y.-T. Lin · I.-C. Tsai · W.-L. Tsai (ه) ·

M.-C. Chen · P.-C. Lin - S.-W. Chan

Department of Radiology, Taichung Veterans General

Hospital, Taichung, Taiwan

e-mail: flycatcher.tsai@gmail.com

Y.-T. Lin · I.-C. Tsai · W.-L. Tsai

Faculty of Medicine and Institute of Clinical Medicine,

National Yang-Ming University, Taipei, Taiwan

T. Lee

Lee's General Hospital, Lee's Medical Corporation,

Taichung, Taiwan

M.-C. Chen · P.-C. Lin

Department of Radiological Technology, Central Taiwan

University of Science and Technology, Taichung, Taiwan

S.-W. Chan

Biomedical Informatics and Biomedical Engineering

Department, Feng Chia University, Taichung, Taiwan
The affiliations of the authors were incorrectly displayed and an important footnote was missing. The correct information is published below and should be treated as definitive by the reader.

Furthermore, a typographical error was introduced in the first sentence of the section "Acute pulmonary embolism and pulmonary infarction" and in the caption of Fig. 2, where thromboembolic must have read thromboemboli. 